\title{
Reform and Practice of Order-oriented Curriculum System in Rural Areas for Medical Students
}

\author{
Zhihong Zhong', Jun Yan², Min Liu*, ${ }^{2}$ \\ ${ }^{1}$ Gannan Medical University, Rural (community) Research Center, 341000 \\ ${ }^{2}$ First Affiliated Hospital of Gannan Medical University, 341000
}

Keywords: rural areas; order-oriented curriculum; medical students; curriculum system; reform and practice

\begin{abstract}
According to requirements and qualification standards of medical personnel position in rural medical and health units, this paper carries on the beneficial exploration and the practice of reform on rural order-oriented curriculum system for medical students, optimizes teaching content, constructs core curriculum, and strengthens practical teaching, in order to cultivate rural medical and health personnel in our country.
\end{abstract}

In 2010, the National Development and Reform Commission and other seven departments started the implementation of a program of free cultivation of order-oriented medical students in rural areas, focusing on training personnel engaged in general practice in township health centers and the following medical and health institutions, who has become an important source of rural general practitioners in the central and western regions.

In the process of rural order-oriented medical personnel training and reform, most of colleges and universities follow the traditional teaching mode of clinical medicine, while paying attention to the improvement of theoretical teaching, clinical diagnosis and treatment skills in the setting of the curriculum system, neglecting the comprehensive reform of personnel with professional knowledge, professional skills and professional accomplishment as healthcare providers, health plan and decision makers, health knowledge disseminators, community health advocates and health resource managers ${ }^{[1]}$. In order to further reform the teaching mode of order-oriented medical students in rural areas and to meet the demand of rural medical service, it is necessary to reform the curriculum system of rural order-oriented medical students. In the past 7 years, Gannan Medical University investigated the status quo of rural medical and health services as well as the requirements of medical staffs' positions in rural medical and health units. With reference to the undergraduate medical education standards of clinical medicine, Gannan Medical University carried out a series of reforms on order-oriented curriculum system in rural areas for medical students.

\section{Optimize the Curriculum System}

Under the guidance of the Professional Construction Steering Committee, the questionnaire survey of 797 rural medical staff positions in 64 rural medical and health units of 18 counties (cities and districts) under the jurisdiction of Ganzhou City was conducted. The investigation and study of rural medical units were conducted and industry experts were invited Meetings and other means of meeting, In order to summarize and summarize the post ability and requirements of ORCs in rural areas, refer to the "China Undergraduate Medical Education Standards - Clinical Medicine (2016 Edition)" to determine that ORs in rural areas should have scientific and academic skills, clinical competence, and health social skills, professionalism and other basic requirements, based on this, the corresponding teaching modules are set up, including modules of ideological and moral courses, humanities and social sciences and behavioral sciences, natural science modules, biomedical modules, public health modules, clinical medical modules and professional development modules class).

According to the survey results of medical staffs' ability requirement in rural medical and health 
institutions, most rural medical staff attach great importance to biomedical and clinical medicine courses, And the ideological and moral curriculum, humanities and social sciences and behavioral science courses, public health courses are not enough emphasis. Most rural medical staff think that the ratio of theoretical class hours to practical class hours ranges from 1: 0.8 to $1: 0.5^{[2]}$. In each curriculum module, in order to meet the rural medical and health service needs and job competency requirements, the principle of "necessary, sufficient and practical" is adopted, the proportion of compulsory courses should be reduced moderately, the types and quantities of elective courses should be expanded, the biomedical courses should be reserved, main course of medical courses, strengthen public health courses, appropriate to increase the humanities and occupational health related courses, and pay attention to strengthening the practice teaching, construction of clinical and basic integration, prevention and clinical integration, integration of humanities and medicine course system.

Under the guidance of the Professional Construction Steering Committee, the professional teachers, together with industry experts, will optimize the curriculum system of oriented medical students in rural areas according to the requirements of rural medical and health service, the qualifications of national practitioners and the examination outline, and select relevant teaching contents. First, we will focus on the additional health education in rural areas such as "primary medical treatment and treatment", "basic medical clinical skills", "primary medical rehabilitation" and "primary medical Chinese medicine", for the common rural health problems, "basic health care management" and other public health courses were modestly increased, and primary-level medical teaching materials published by people's health publishing house were compiled. The second is to enhance education in the courses of ideological and moral cultivation and medical humanities such as "the road to benevolent medical treatment", "red hygiene" and "Jinggangshan Spirit", It emphasizes that teaching contents such as medical humane spirit, professional ethics, occupational attitudes and occupational values should be integrated into the teaching of specialized courses so as to cultivate the spirit of humane care for students and establish the awareness of "rooted in rural areas and serve farmers." The third is to integrate the qualification standards, knowledge points and skills requirements into relevant courses. Through a series of targeted courses and optimized teaching contents, the curriculum and teaching contents are more in line with the qualifications of practicing doctors and the passing rate of graduates' qualification examination is improved.

\section{The Construction of Core Curriculum}

According to the rural target-oriented medical personnel training objectives, soliciting professional advice from the Steering Committee and employing units on the ability of directing medical graduates in rural areas, the core courses are: Internal Medicine, Surgery, Obstetrics and Gynecology, Pediatrics, Grassroots Medical Clinical Skills, Primary Medical Treatment and other 6 courses.

In order to highlight the applicability and practicality of the core curriculum, strengthen the practical ability of students and training of clinical operation skills, and intensify the reform of the curriculum of basic medical clinical skills and primary medical treatment and treatment. Basic clinical medical skills in the form of integrated school training to make effective use of the school's OSCE to simulate the clinical practice in rural areas to carry out teaching, early exposure to clinical early contact with the rural areas, early exposure to general subjects, enabling students to achieve clinical teaching and rural medical schools The actual zero contact, improve the clinical skills of students operating ability ${ }^{[3]}$.

\section{The Integration of Course Content}

The experimental teaching of rural oriented medical students is separated from the original theoretical teaching of basic medical disciplines, based on experimental techniques, breaking the boundaries of disciplines and the existing curriculum framework, and having a strong internal connection to the content of different disciplines Basic experimental course integration, Unified 
integration for the medical laboratory science, including the introduction of medical research methods, medical morphology skills, medical skills, medical analysis and detection skills, medical clinical basic skills and so on. The basic theory and method of medical science research include the basic content, elements and principles of medical research design, the basic principles and basic methods of medical experimental design, the basic operation of medical experimental animal and animal experiment, medical research design and methods; statistical data of medical research; medical literature retrieval, medical essay writing, scientific research appraisal and evaluation of teaching content; Medical morphology and skills to human and pathogenic morphology of the main structure, its content mainly in embryology, pathology, medical microbiology, human parasitology and diagnostic "bone marrow cytology" and other content as the basis; Medical skills and skills to human body functions and changes as the main line, with physiology, pathophysiology, pharmacology and other content-based; medical analysis and detection skills: the commonly used analytical and experimental techniques as the main line of cell and molecular biology, immunology, genetics and other disciplines as the basis; Medical basic clinical skills: the clinical basic skills and basic operations as the main line, based on the contents of diagnostic and surgical summary of the basic obstetrics and gynecology, anesthesiology, ophthalmology ENT and pediatrics clinical basic skills Included.

The experimental teaching contents of each experimental course can be divided into three levels: basic skills, professional applied skills, comprehensive applied skills and innovative abilities, focusing on gradual practice training and effectively cultivating students' comprehensive analytical ability and innovative ability, had a better teaching effect.

\section{Reform of Teaching Methods}

In the teaching process, we emphasize "taking students as the center", adopting modern information technology teaching methods, emphasizing problem guidance and interest enlightenment, paying attention to the cultivation of critical thinking and autonomous learning ability, and paying attention to the development of communication and collaboration awareness. Positive use of heuristic, discussion and other education and teaching methods, such as PBL, CBL, network-assisted teaching.

We set up a professional curriculum of "Benevolent Doctrine" and set up multi-disciplinary teachers such as medical science, law science, pedagogy and art in the course. Through joint participation in combination, teaching organization in small classes, teaching methods, teaching specialization, greatly enhance the students' interest in learning and effectiveness. Eaching through life narratives and case discussions to enhance students 'professional identity, develop students' professional attitude, professional ethics and professional values. Make full use of the second classroom, mining campus culture, local characteristics of resources, social practice, volunteer service and other educational functions, the professional accomplishment cultivation into students' extracurricular activities. With the spirit of the Soviet Union, the spirit of Jinggangshan, the spirit of Red Army Medicine and the motto of school motto, we sing the red hygienic culture and inherit the red gene; invite outstanding alumni to return to school to give lectures and tell the story of "Gan Yi People"; strengthen the professional ideal and conviction; Humanities Festival, carry out the most beautiful village physician survey, grass-roots township hospitals survey, relatives and friends do the health management files, volunteer services, "two investigations and two do" social practice activities, all-round, multi-channel vocational literacy education ${ }^{[4]}$.

\section{Strengthen the Practice of Teaching}

Practical teaching includes: Experimental teaching: including introduction to medical research methods, medical morphology skills, medical functional skills, medical analysis and testing skills, medical clinical basic skills and so on, a total of 320 hours. Clinical probation: Including clinical courseware trainee, dispersed trainee, focus on trainee, a total of about 160 hours. Basic clinical skills and skills of primary care: Through primary grassroots clinical skills and diagnosis and 
treatment of basic skills training, students receive a systematic and standardized basic operation and skills training before they enter the clinical practice, and get to know the basic principles of primary clinical diagnosis and treatment Methods, familiar with their working procedures, a total of 90 hours. Preventive medicine practice: Deepening students 'understanding of public health services and medical related knowledge by arranging students' practice in the community, epidemic prevention stations and disease control centers, and establishing a concept of student prevention and health services for the general public, a total of about 50 School hours. Clinical graduate internship: students participate in graduate internship for about 50 weeks. Other practical teaching links include extra-curricular research capacity training, entrance education and military training, community service and social practice, for a total of 6 weeks.

The establishment of grassroots practice teaching base teacher training mechanism. Arrangement of affiliated hospital experts for teaching supervision and demonstration teaching. The backbone of the backbone of the training base for the organization of general practitioners, CDC experts invited, grass-roots doctors and school theory teaching teachers joint teaching, teaching content and job requirements to achieve seamless docking. Guided by grassroots clinical capacity, we constructed a three-level grassroots practice teaching base group supported by school affiliated hospitals, county-level general hospitals, township (community) health centers and CDCs, and arranged a full course "Early understanding of the grassroots, early exposure to general practice, early arrangements for internship," the "three early" practice teaching, improve the level of clinical primary school students ${ }^{[5]}$.

\section{The Effectiveness of Curriculum Reform}

Gannan Medical University in the reform of rural order-oriented medical students teaching mode and its curriculum system, personnel training has reached a new level. 2015,2016 undergraduates $100 \%$ enter the base to participate in standardized training of general practitioners of medical residents. Third-party evaluation report shows that graduates quality appraisal unit accounted for $95.7 \%$ of the overall evaluation of outstanding, graduates ideological quality assessment rate of $92.86 \%$ outstanding, knowledge structure evaluation outstanding rate of $88.1 \%$, job evaluation of outstanding $71.4 \%$.

The direct result of the reform gave birth to the free policy of order-oriented medical students in Jiangxi Province and Ganzhou City. In 2010, Jiangxi Province promulgated the "Implementation Measures on Targeted Cultivation of Medical Students in Township Health Centers" in Jiangxi Province, and from the beginning of the year, it directed to train medical students in township hospitals. Since 2014, Ganzhou City has introduced a free training program for undergraduates for ORC clinical undergraduates, and the school has been training 400 undergraduate medical students for the orders of township hospitals in the city for two consecutive years. The number of students enrolled increased from 99 in 2006 to 2,285 in 2016. The enrollment coverage increased from 94 townships in 19 counties in Ganzhou City in 2006 to 1,530 townships in 100 counties (cities) in Jiangxi Province in 2016, The total number of undergraduate enrollment accounted for $56.3 \%$ of the total enrollment of similar level in Jiangxi Province.

Gannan Medical University based on the rural medical and health institutions to meet the requirements of medical personnel positions to further integrate the national licensing system and the requirements of the examination syllabus and other requirements, combined with the views of experts and employers, rural order-oriented medical personnel training system reform , To cultivate the general medical talents under the condition of "getting under, staying and developing in rural areas", promoting the reform of education and teaching in the mode of cultivating rural order-oriented medical personnel in rural areas, realizing the coordinated development of knowledge, skills and literacy, The pace of teaching reform of general practitioner education at the grassroots level. 


\section{References}

[1] Xu Yan, Wang Weimin, Wang Xian. Exploration and practice of general medical course system [J]. Journal of Medical Education, 2016,15 (11): 1094-1097.

[2] Zhong Zhihong, Yan Jun, Huang Aimin, et al. Investigation and research on five-year free orientation clinical medicine course setting [J]. Chongqing Medical University, 2013,42 (11): 1308-1309.

[3] Liu Jicheng, Zhang Xiaojie, Yun Changhai, et al. Exploration and practice of three-oriented training model reform aimed at the future development of medical students [J]. China Higher Medical Education, 2014 (4): 1-3.

[4] Tang Ping, Wang Lunan, Tang Hongchuan. Construction of medical humanities education model [J]. Chinese Medical Ethics, 2014,27 (2): 267-268.

[5] Tang Zhiming, Zhang Shaohua, Zheng Heng, et al. Three-year clinical medical specialty curriculum system reform based on the needs of primary health posts [J]. Chinese Medical Education Journal, 2013,33 (3): 358-361. 